\title{
IJCL
}

\section{Electrospinning and spraying of biomolecules and cell-derived bodies}

\section{Prof Gareth Williams}

UCL School of Pharmacy

Email: g.williams@ucl.ac.uk; Twitter: @grwUCL 


\section{What can we electrospin?}

Mass (g)

$10^{-22}$

Peptides

0

Small

molecules

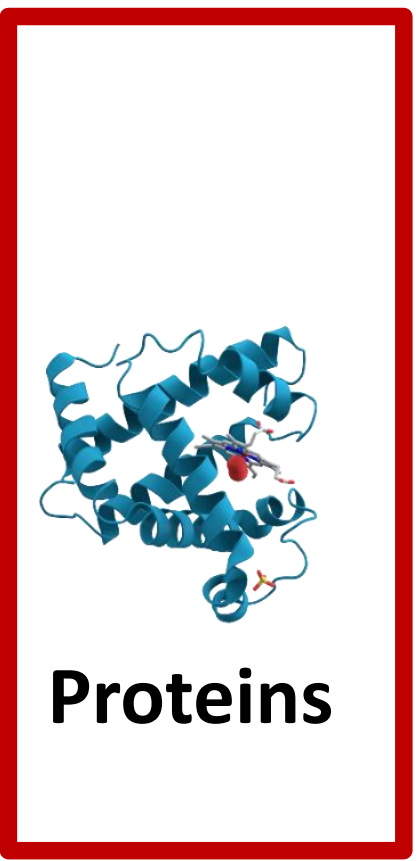

Extracellular vesicles
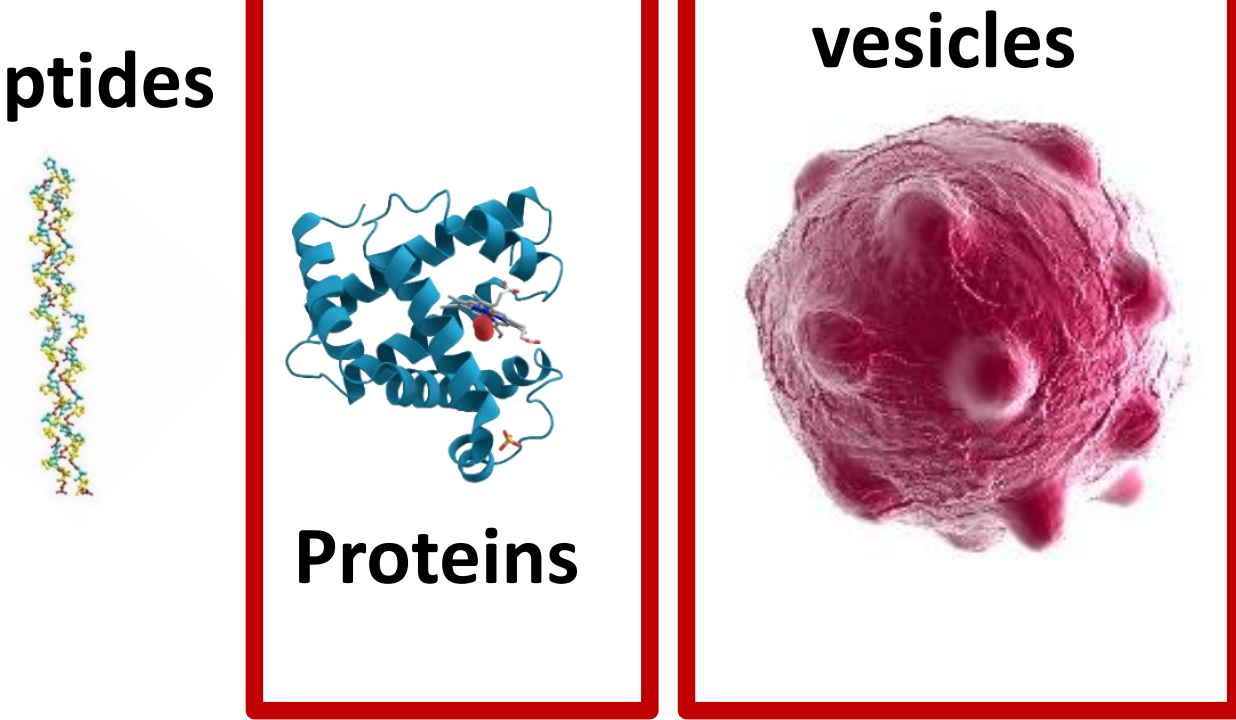

Cells

Number of publications

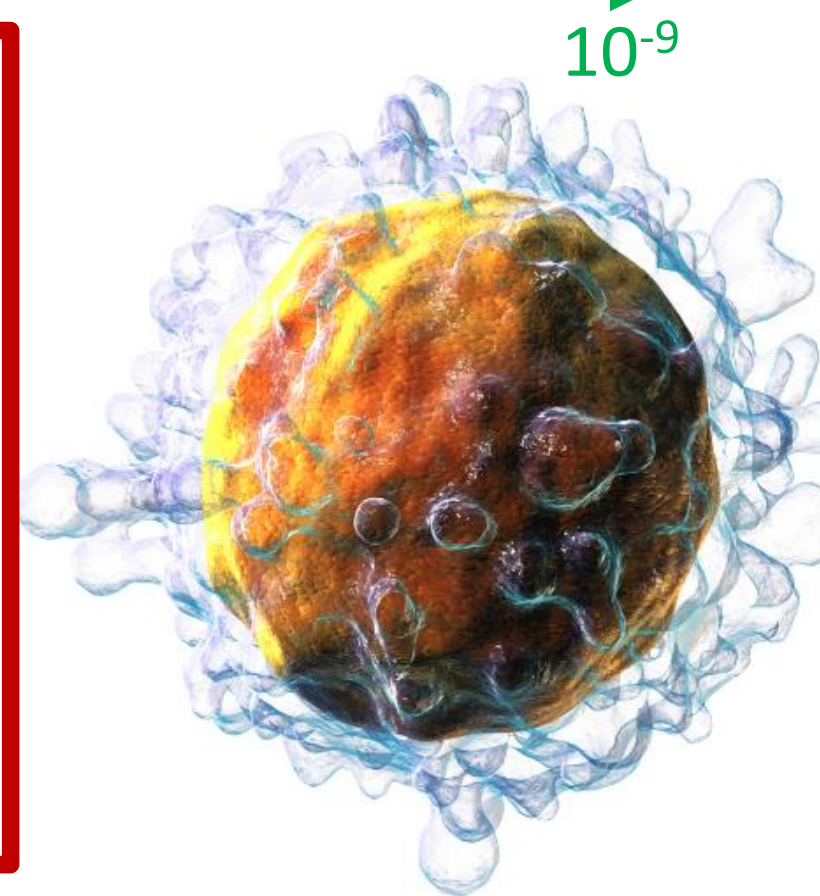


Protein delivery to the eye 


\section{Core/shell bevacizumab loaded fibers}

\section{PCL Beva solution in PBS, buffered at:}

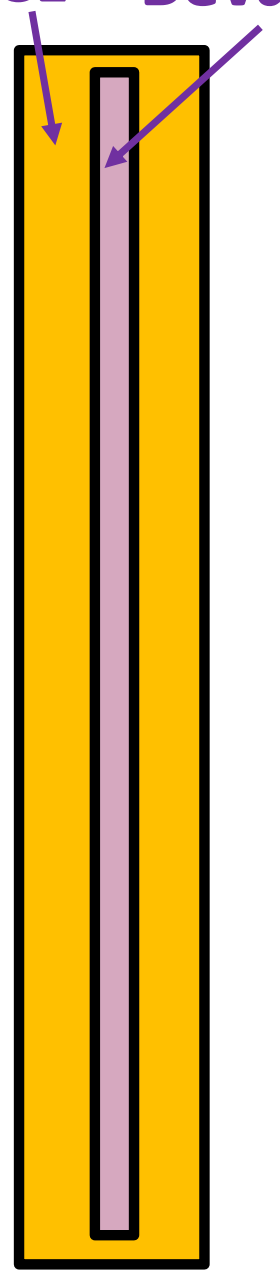

Commercial pH

e)

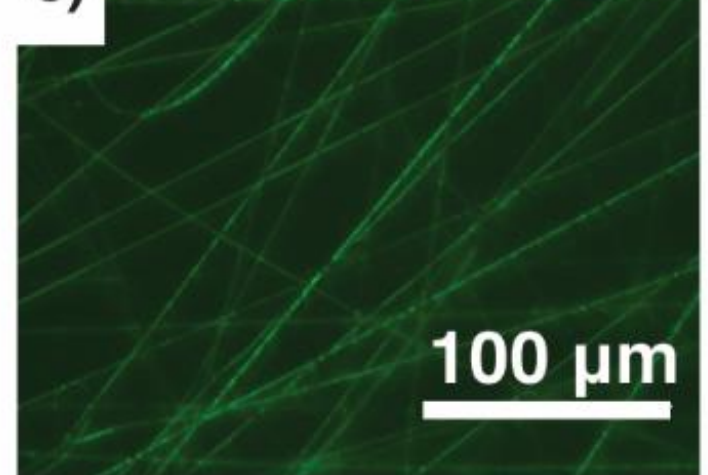

g)

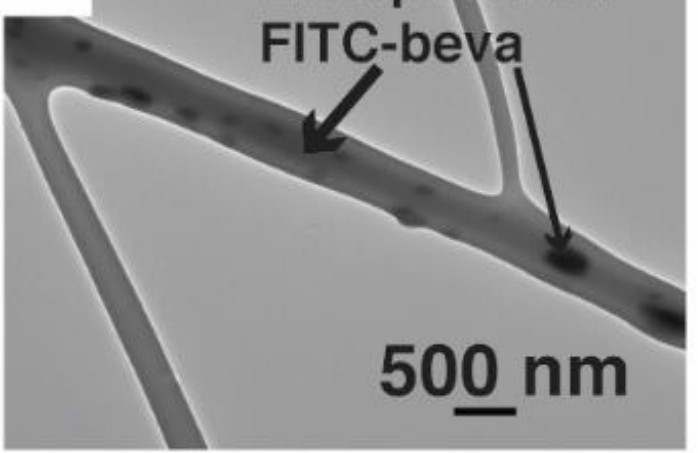

pl

f)

$100 \mu \mathrm{m}$

h)

Encapsulated FITC-beva

$500 \mathrm{~nm}$

Acta Biomater. 2017, 64, 126 


\section{Drug release in an in vitro eye model}

a)

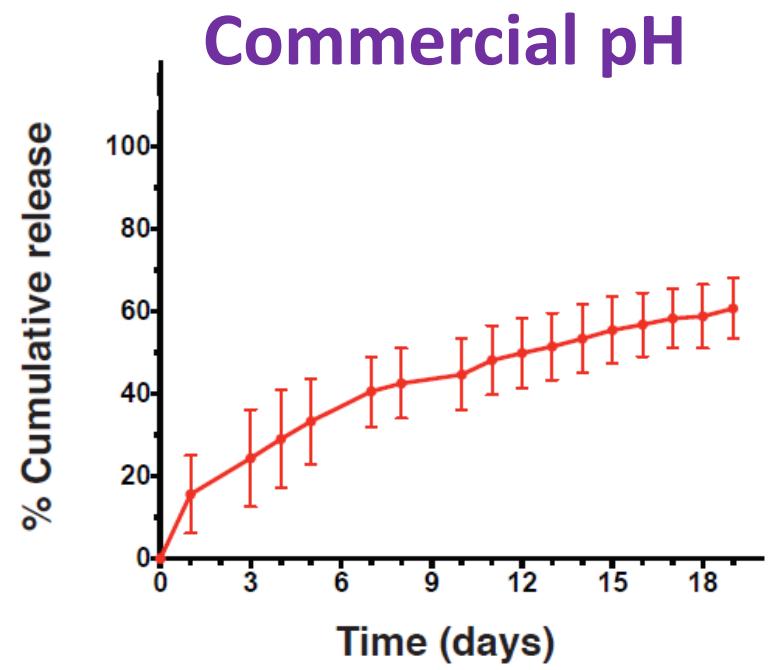

c)

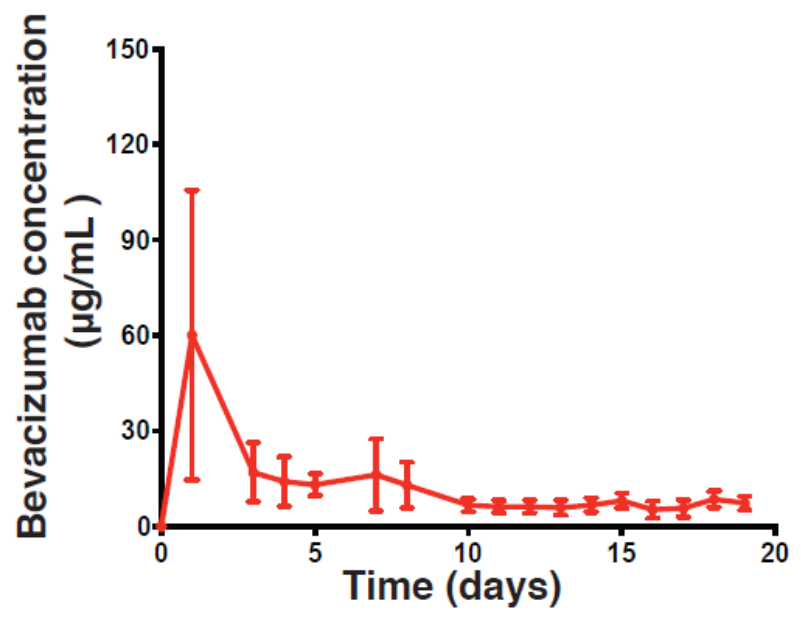

b)

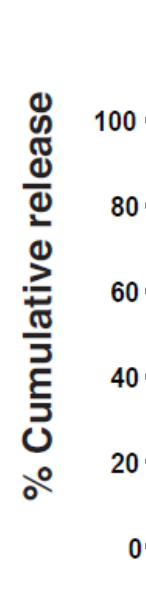

d)

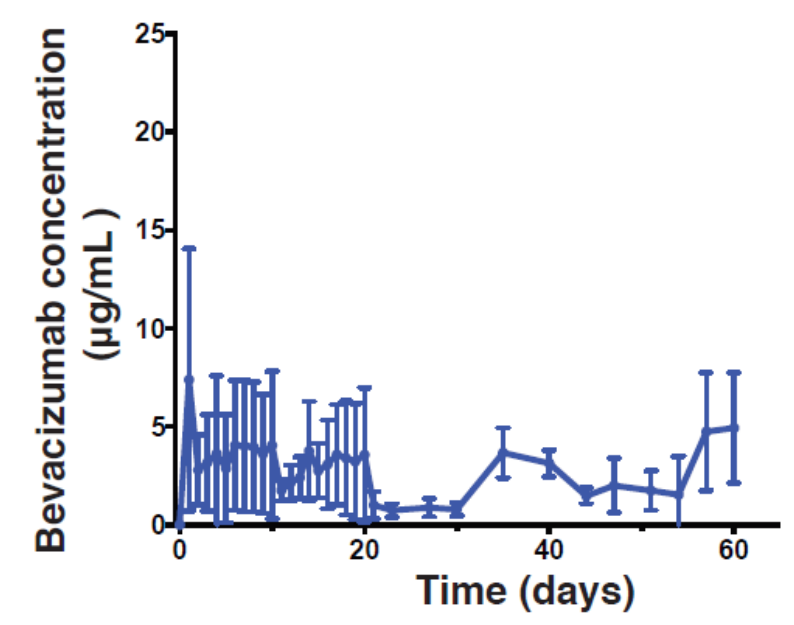

Acta Biomater. 2017, 64, 126 


\section{Protein integrity and binding}

a)

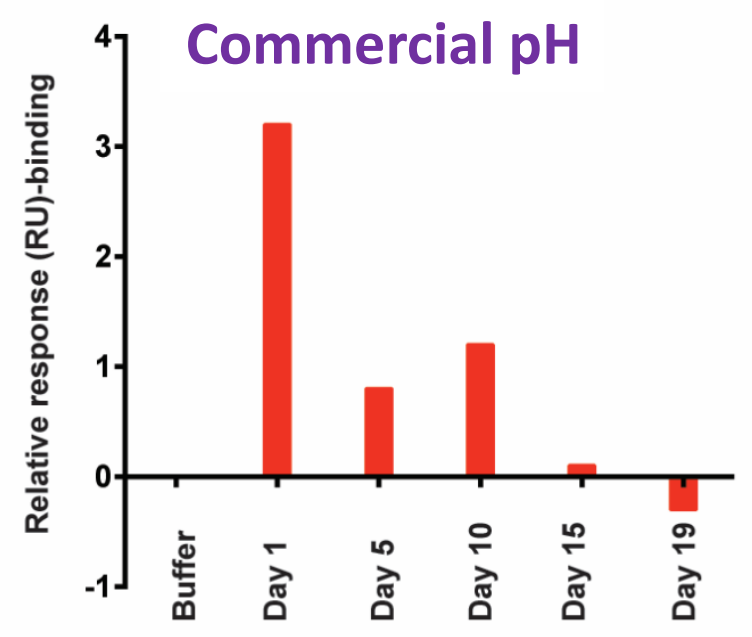

b)

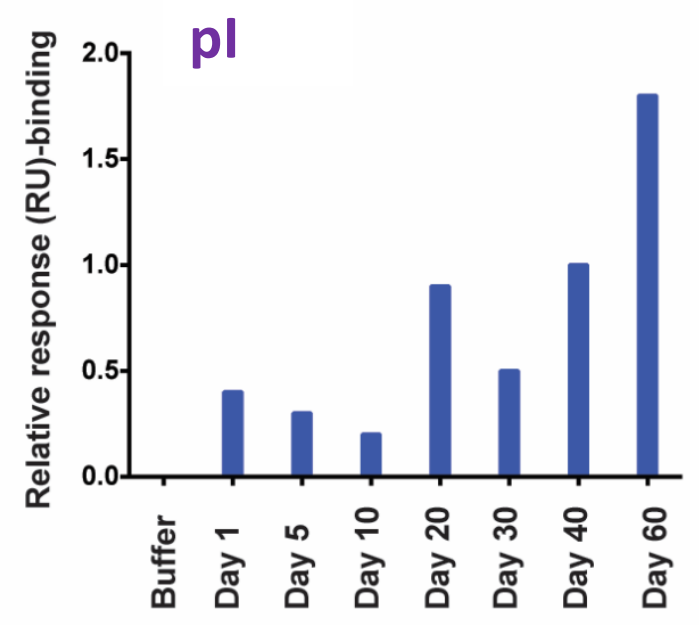

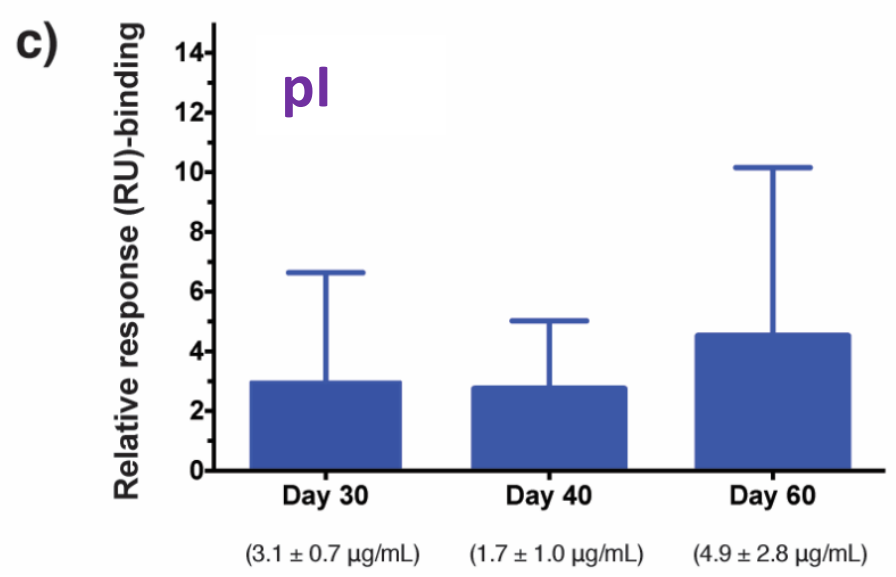

Acta Biomater. 2017, 64, 126 
Intradermal protein delivery 


\section{Microneedles + electrospayed particles?}
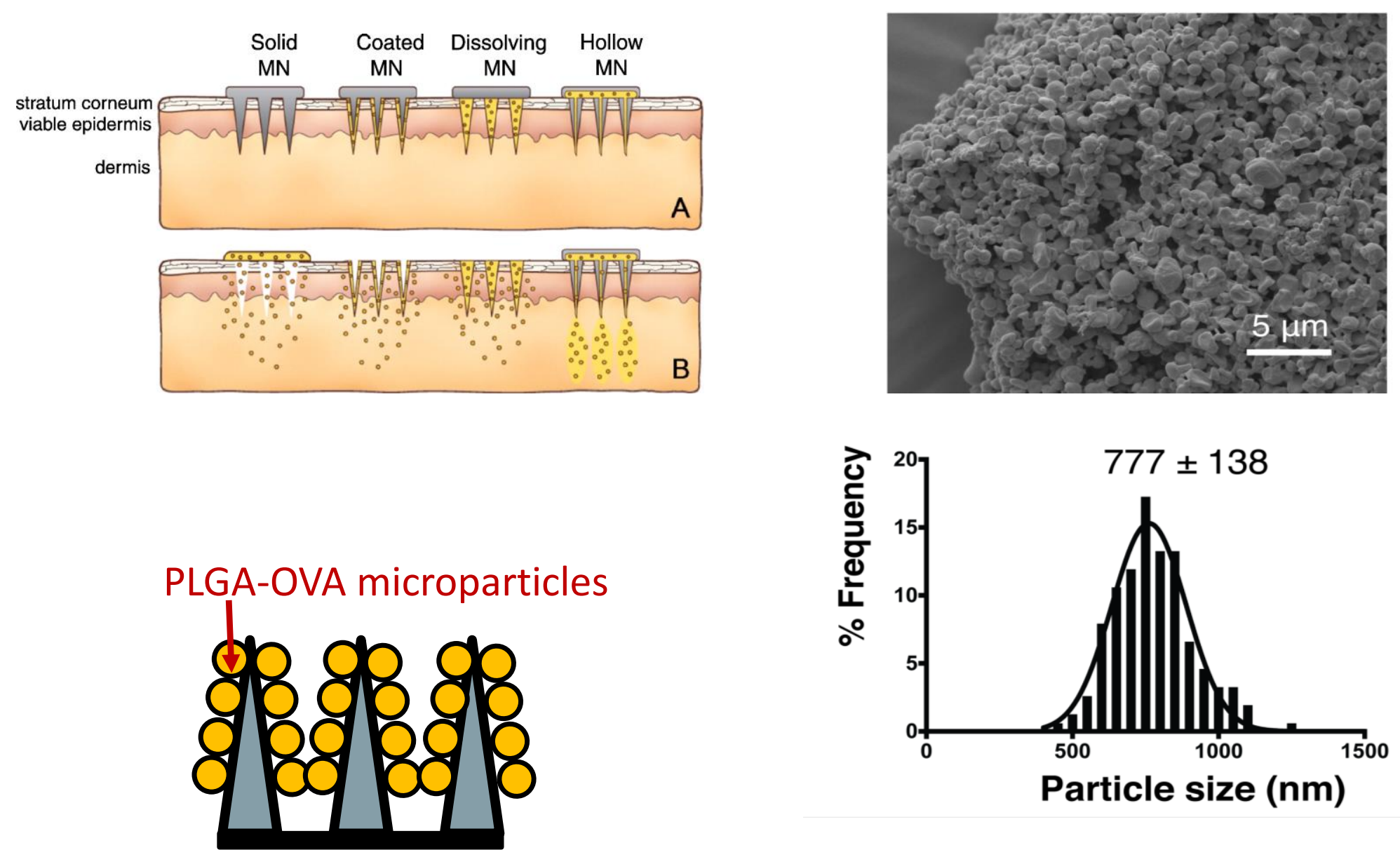

Swellable hydrogel-forming MNs 


\section{OVA release}
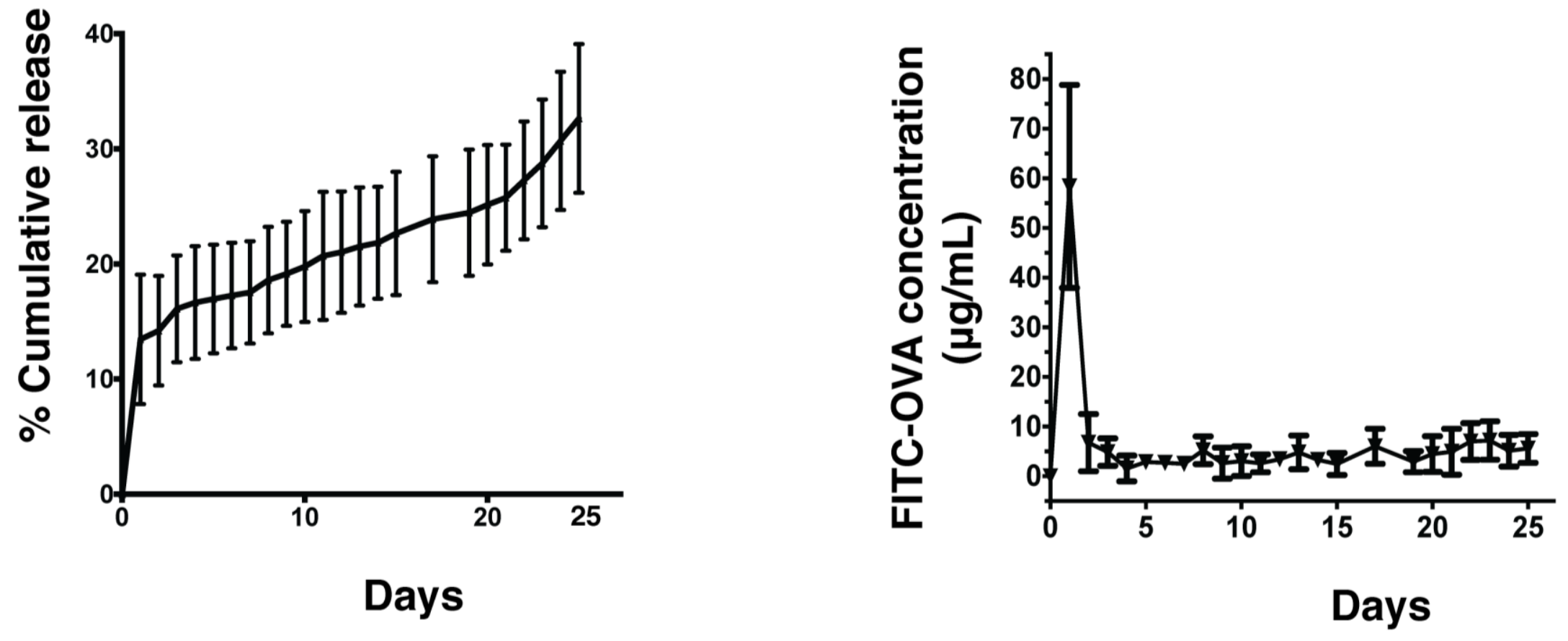


\section{Immunogenicity in vitro}

Human monocyte-derived dendritic cell data
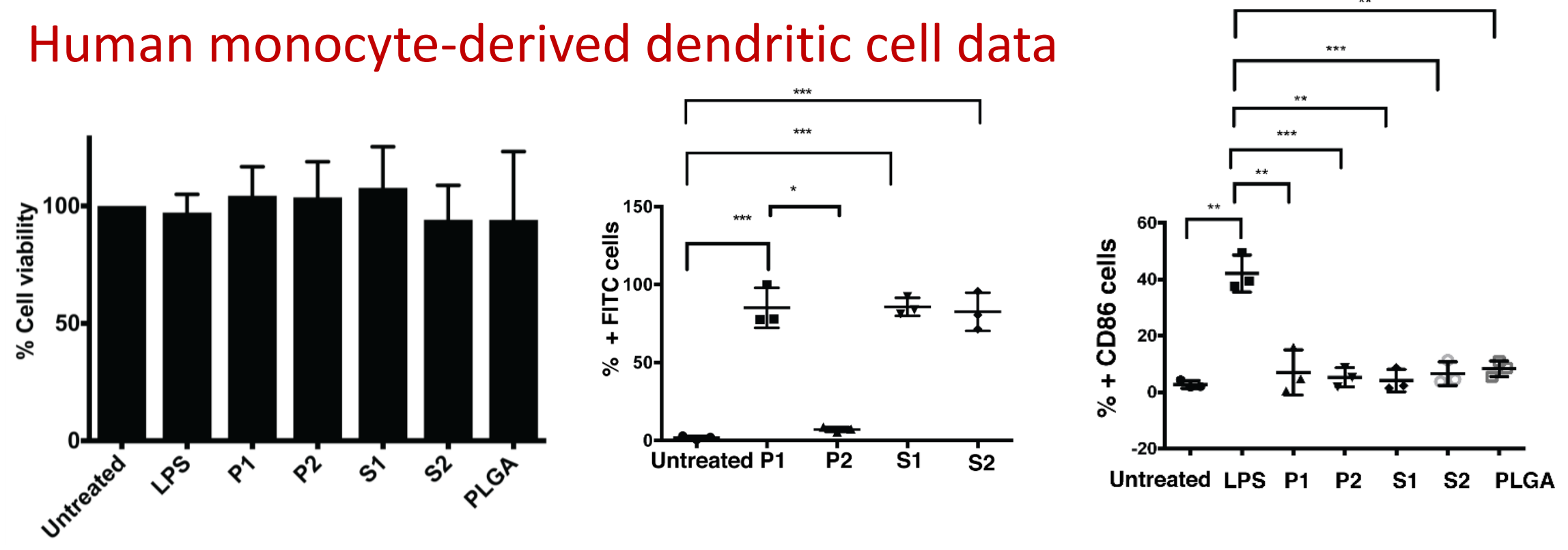


\section{Coating}
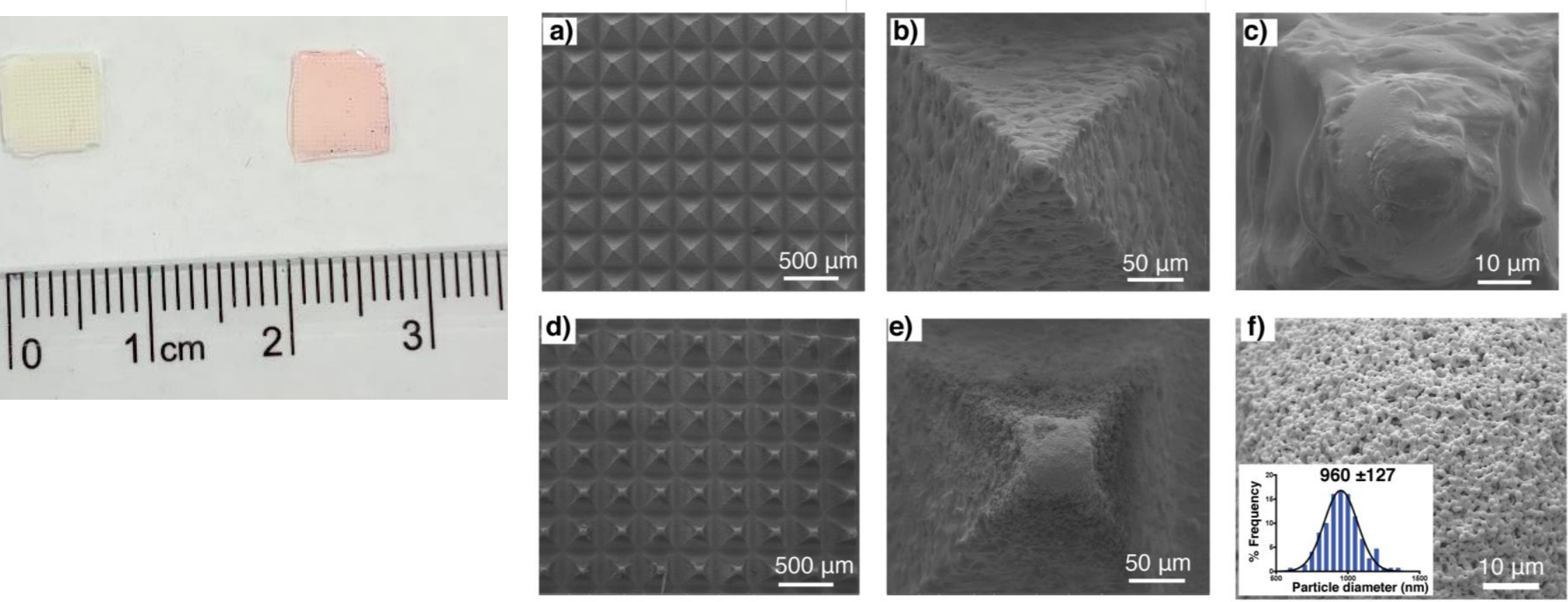

ACS Appl. Mater. Interfaces 2020, 12, 12478 


\section{Coating}
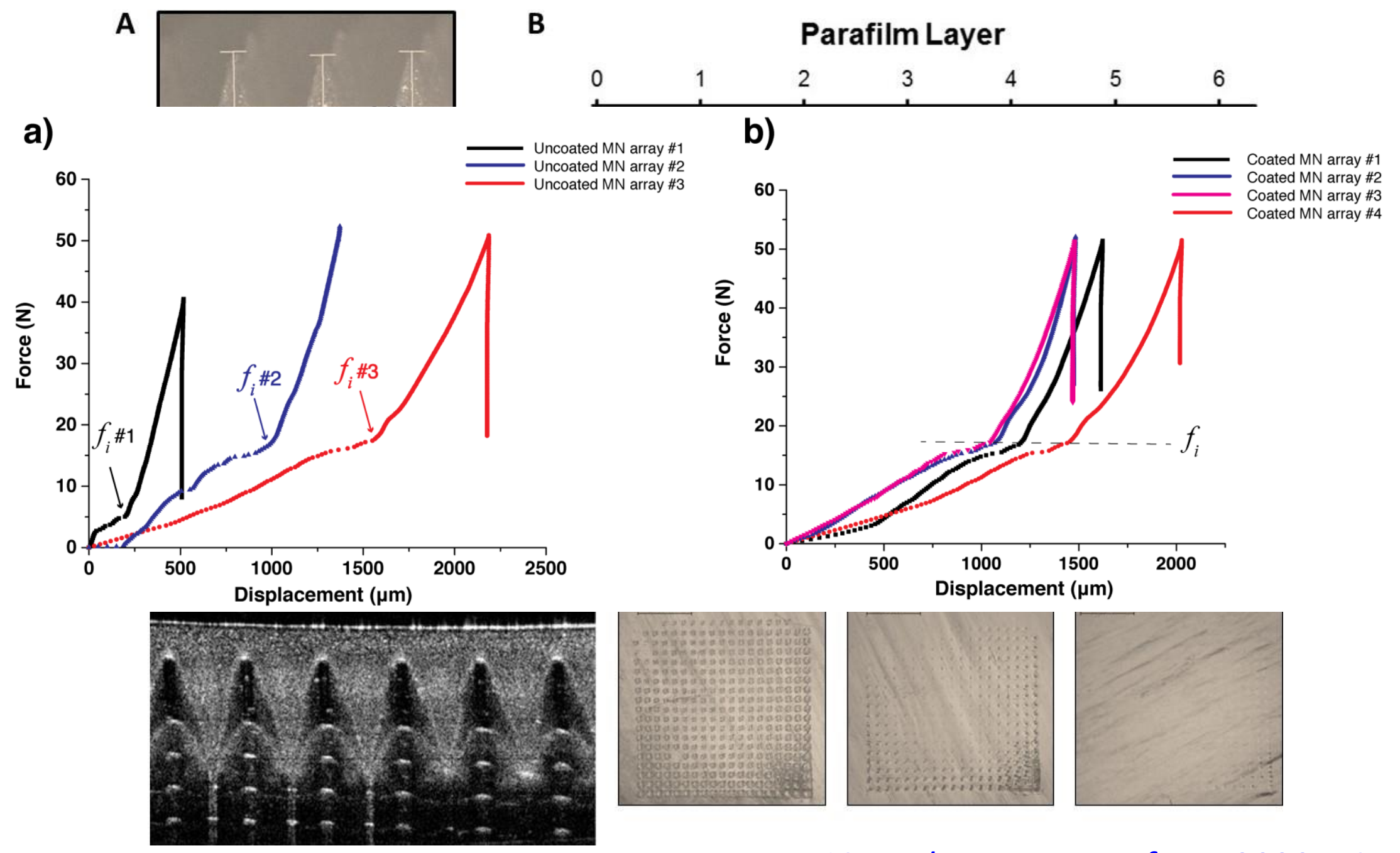

ACS Appl. Mater. Interfaces 2020, 12, 12478 


\section{In vivo immunogenicity?}

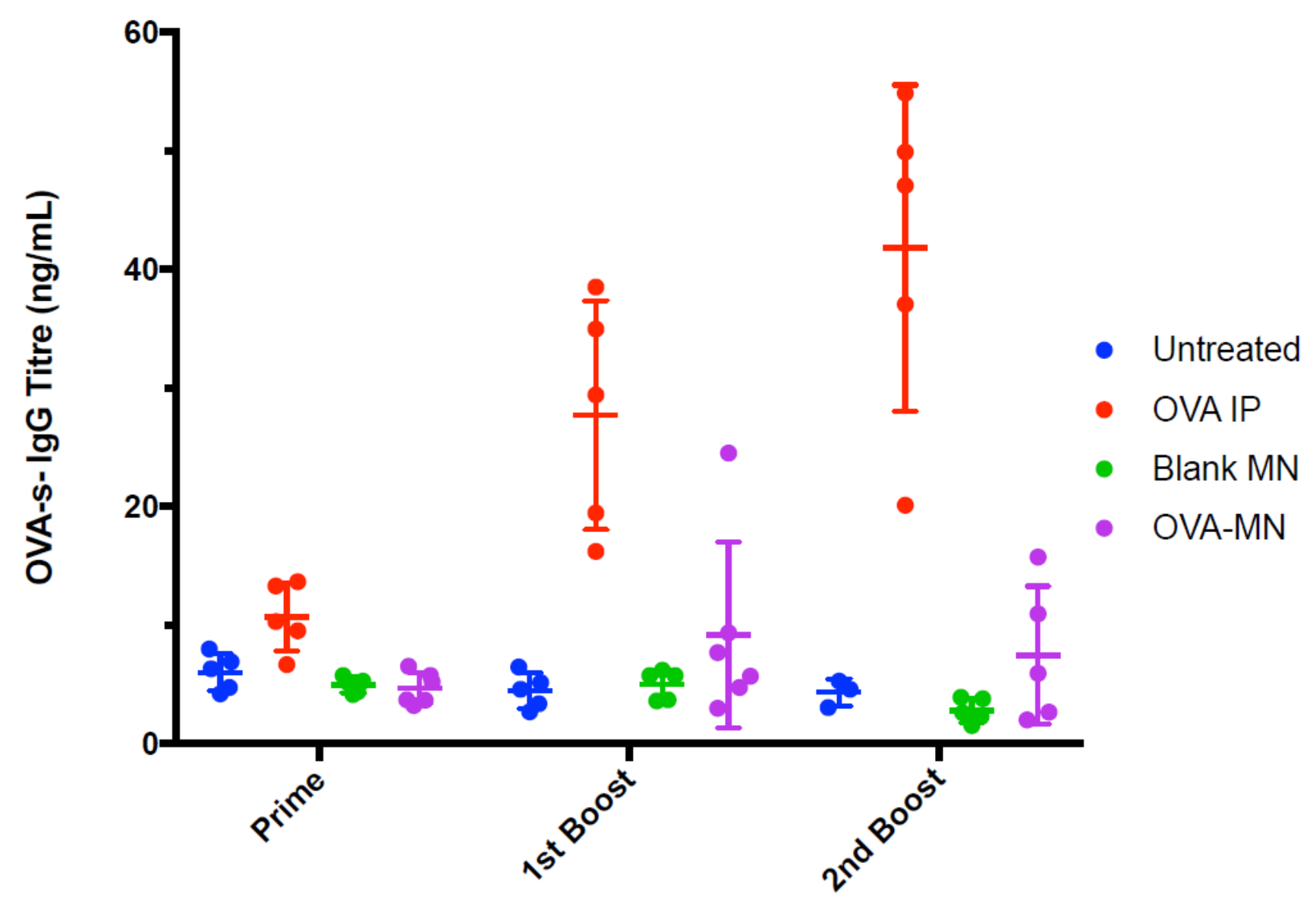

ACS Appl. Mater. Interfaces 2020, 12, 12478 
So can we electrospin extracellular vesicles? 


\section{EV-loaded fibers}
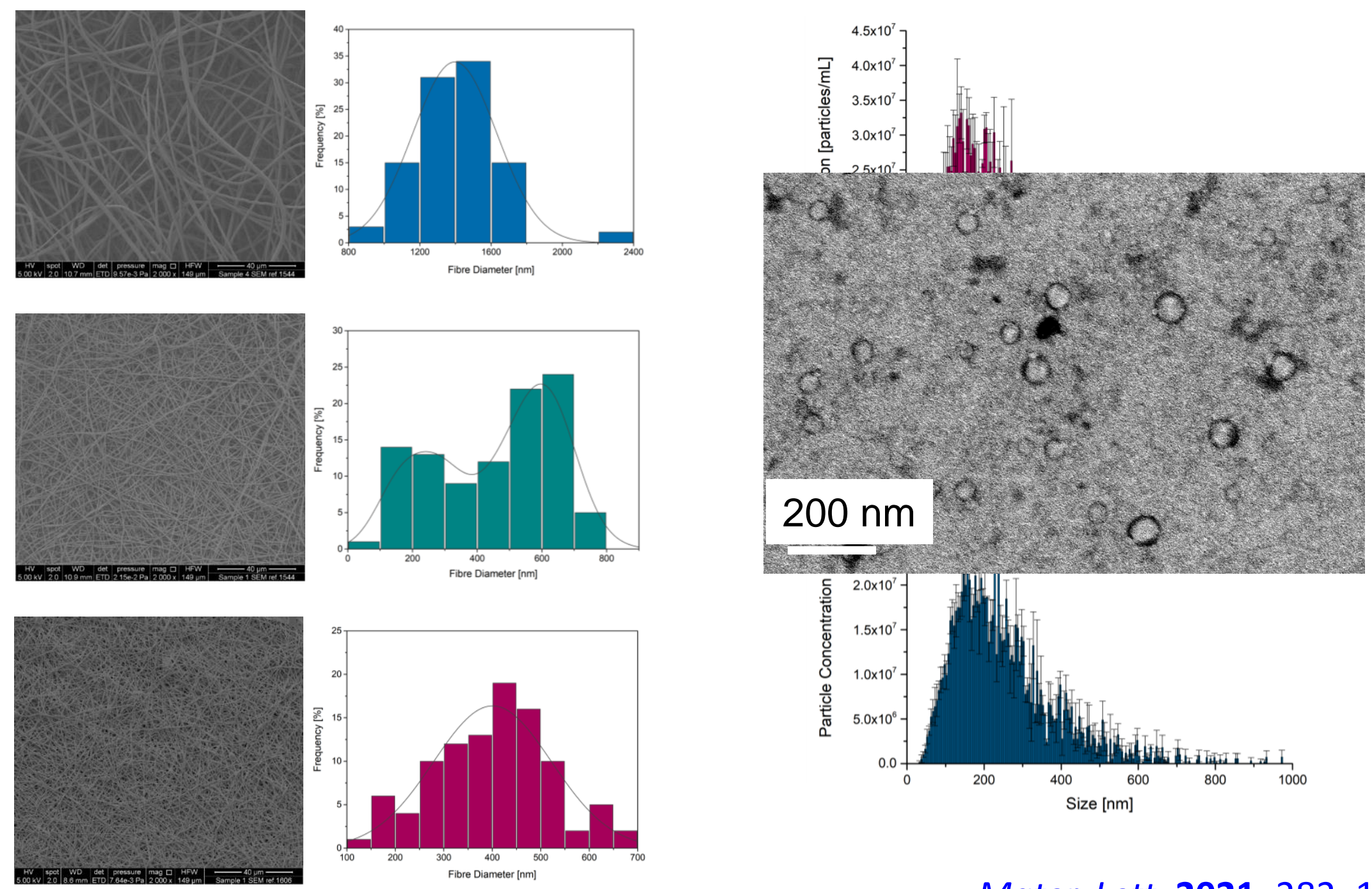

Mater. Lett. 2021, 282, 128671 


\section{What happens to the EVs?}

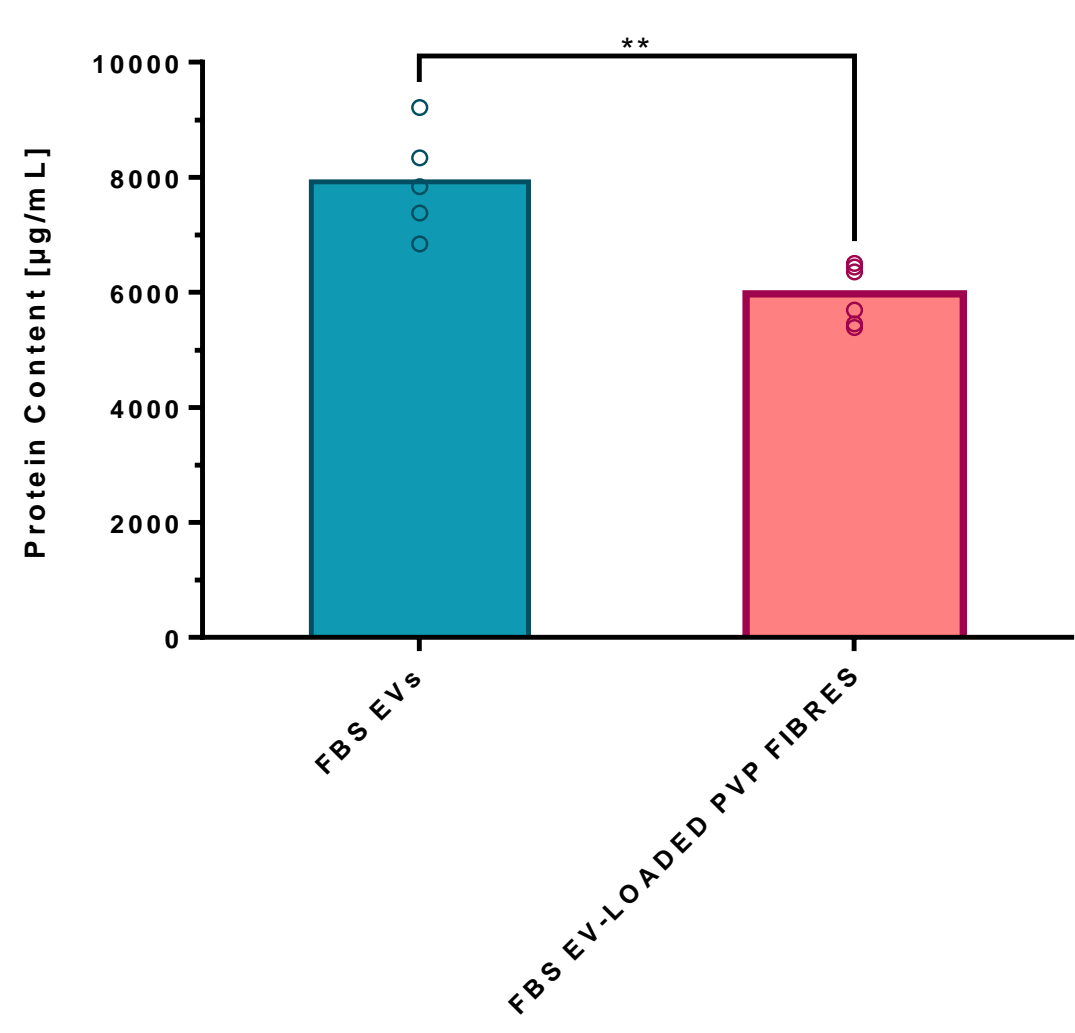

EE $77 \pm 2 \%$

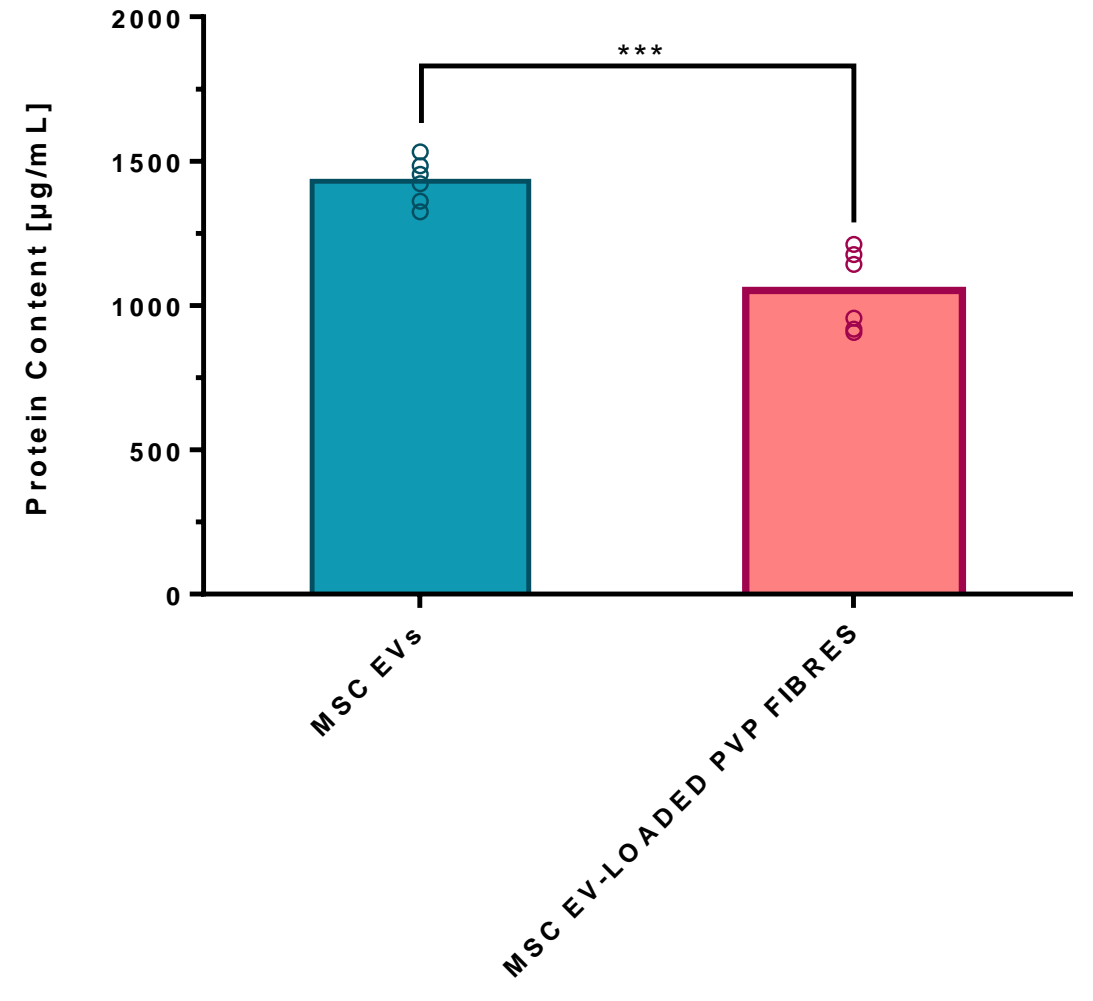

EE $71 \pm 9 \%$

Mater. Lett. 2021, 282, 128671 


\section{What happens to the EVs?}

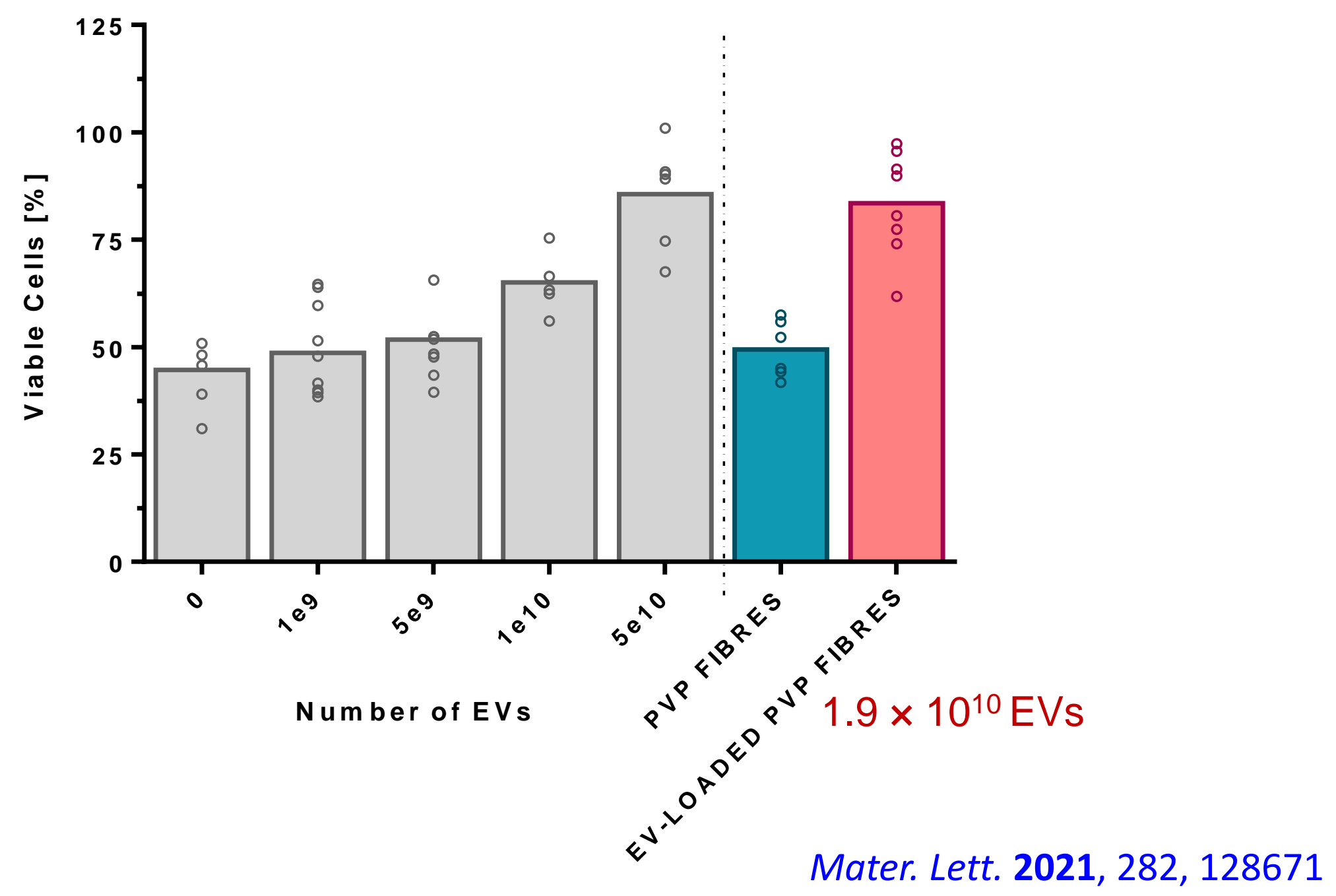




\section{Conclusions}

- Electrospinning/spraying can be used to produce polymer nanofibers/particles loaded with a range of active pharmaceutical ingredients.

- This includes proteins for the treatment of diseases in the eye or for intradermal implantation.

- In both cases we can make minimally invasive implants to give zero-order release over a prolonged time period.

- Extracellular vesicles can also be processed without any damage to their structure or function. 


\section{Acknowledgements}

\section{UCL:}

Prof Sir Peng Khaw

Prof Steve Brocchini

Dr Ukrit Angkawinitwong Dr Eneko Larraneta

Dr Sahar Awwad

Dr Rita Trindade

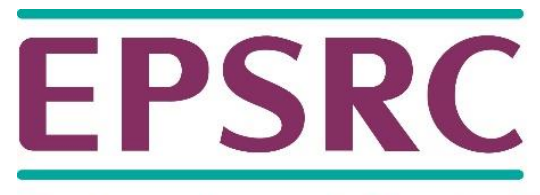

Engineering and Physical Sciences Research Council

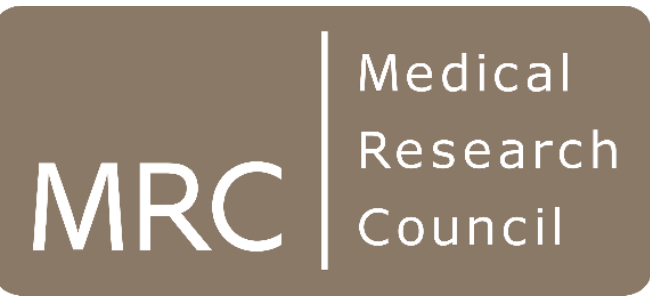

\section{QUB:}

Prof Ryan Donnelly

Prof Helen McCarthy

Dr Aaron Courtenay

Dr Aoife Rodgers

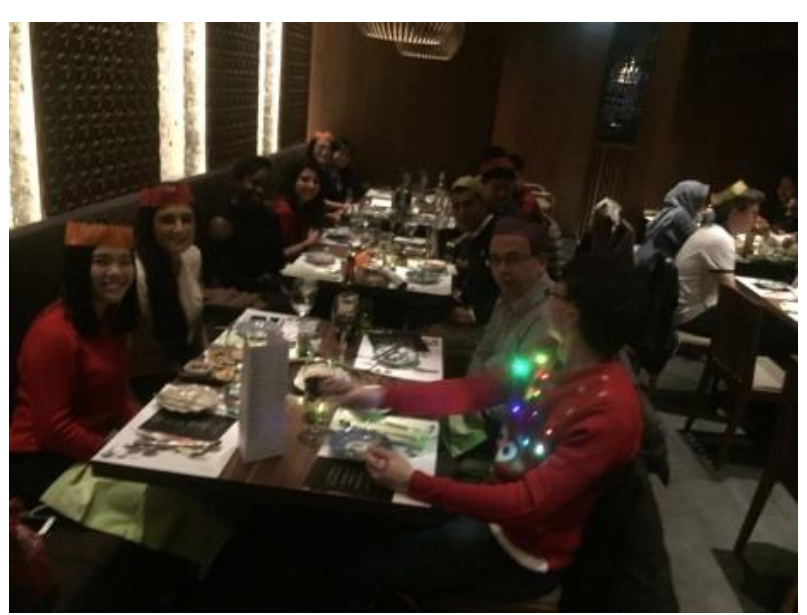

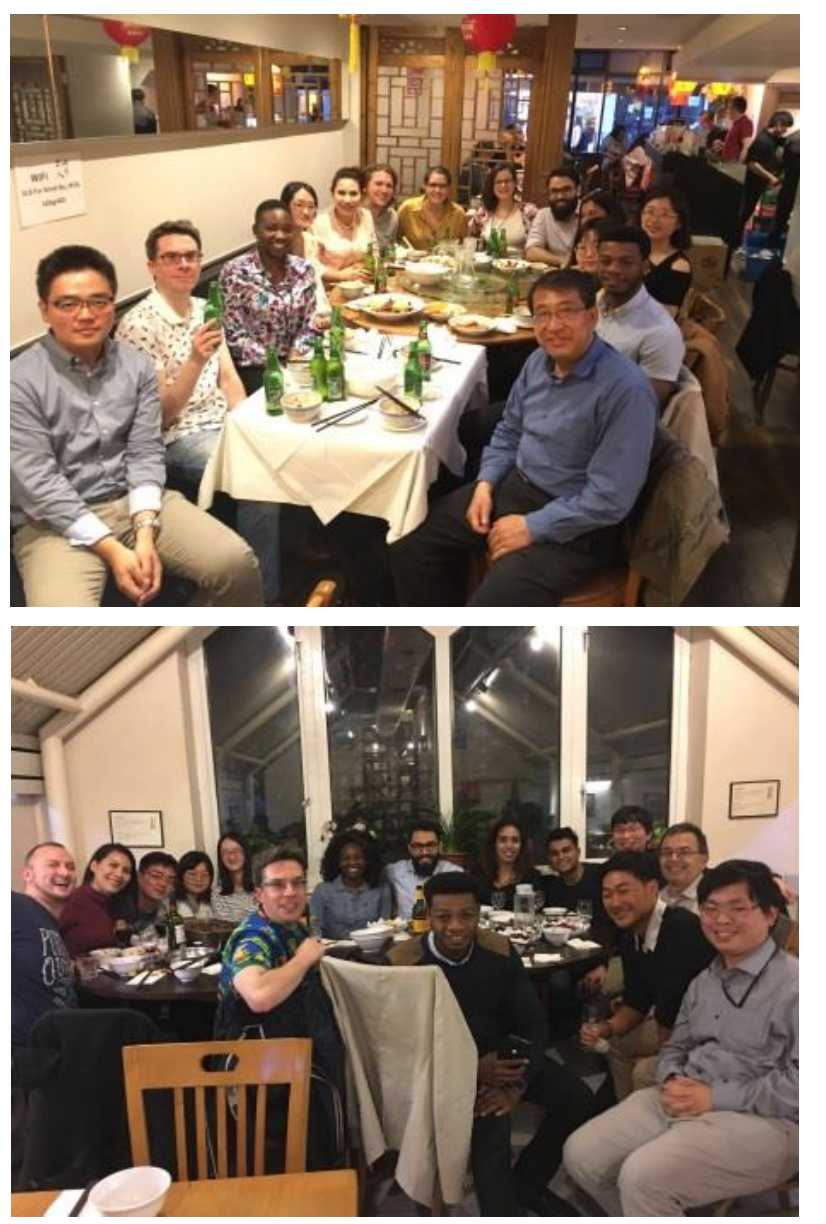




\section{Shameless self-promotion...}

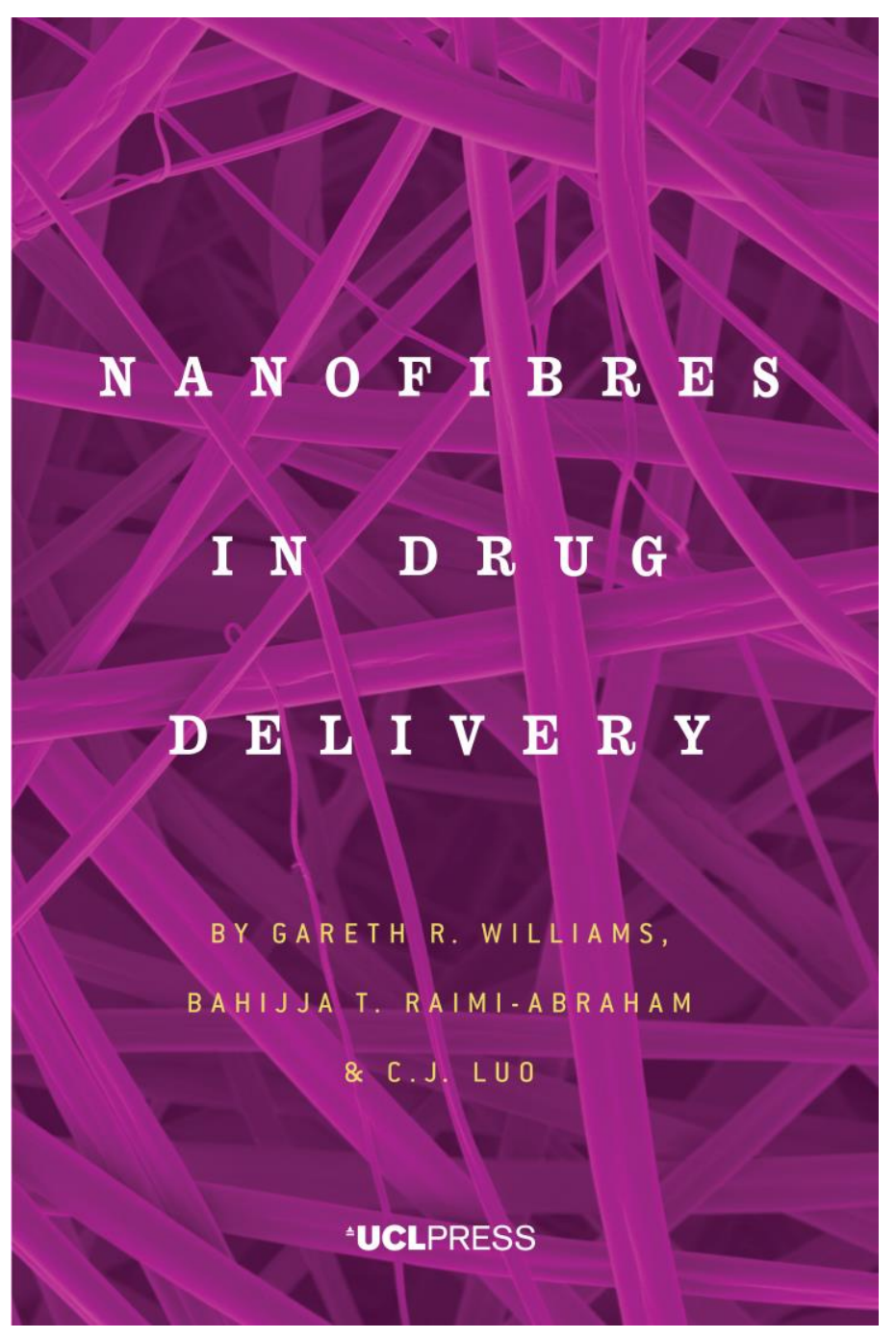

Check out our new book Nanofibres in drug delivery its free to download here:

https://www.ucl.ac.uk/uclpress/browse-books/nanofibres-indrug-delivery

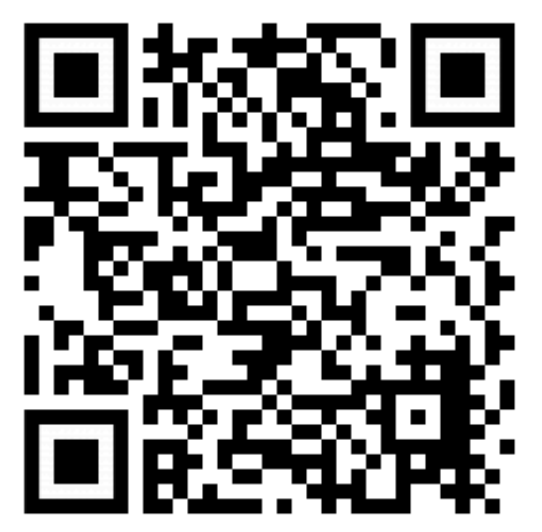

